\title{
THE EFFECTIVENESS OF ETHICS-TRAINING PROGRAMS IN THE BANKING SECTOR
}

\section{The mediation effects of ethical culture, supervision, and enforcement}

\author{
Rima M. Bizri' ${ }^{*}$, Ihab El Bizri2 \\ ${ }^{1}$ Rafik Hariri University - bizrirm@rhu.edu.lb \\ ${ }^{2}$ Credit LibanaisSAL - bizriihab@gmail.com \\ ${ }^{*}$ Corresponding author.
}

Received: 23 September 2018, accepted: 7 October 2018, published: 30 January 2019

\begin{abstract}
Academic and professional interest in organizational ethics-training is on the rise as advances in technology and global reach create increasing opportunities for violations of moral standards. To mitigate risks associated with moral hazard, organizations strive to create an ethical culture by offering formal ethics-training programs. Notably, the literature is rich with studies that confirm a positive effect of ethics-training programs on employee ethical behavior. However, such programs may become mere cosmetics in the presence of a weak ethical culture, a non-ethics oriented supervisor, and lack of policy enforcement. This study investigates the roles played by the afore-mentioned factors on the relationship between formal ethics-training and employee ethical intentions. The quantitative approach is used and data are analyzed using structural equation modeling with IBM's Amos. Important findings are reported and relevant implications suggested.
\end{abstract}

Keywords: Ethics-Training, banking sector, ethical culture, ethical behavior, supervision and enforcement.

\section{INTRODUCTION}

In the banking industry, ethical decision making is of extreme importance since the reputation of a bank is probably just as important as its performance (Krishnan and Sulphey, 2009). Previous studies have argued that ethics training and education may guide individuals when facing ethical dilemmas (May \& Luth, 2012).

This may be the main reason why most banks today offer ethics-training to their employees: for the purpose of ensuring legal and ethical compliance, at a time of increasing accusations of moral breaches in the banking sector. This training is usually mandatory for employees and useful in guiding them through practical scenarios they may face on a daily basis. However, banking procedures may themselves be in violation of ethical standards, thus defeating the purpose of ethics-training.

According to one bank executive, "While employees are taught that certain actions are labeled as unethical and should not be done, some bank procedures require employees to do those actions while conducting regular customer transactions. This confuses employees and undermines the value of ethics-training programs". According to another bank employee, supervisors often ask their subordinates to "temporarily" disregard ethical standards while carrying out certain processes, and when managers or subordinates are caught red-handed, they suffer no negative consequences or punishment of any kind. This lack of ethical supervisory compliance and policy enforcement will likely send the wrong message to employees at all levels and negatively influence their behavior in the short and long run. 
Numerous studies have investigated the impact of Ethics-Training programs on employee behavior in the banking sector (Ferrell, 2016; Warren et al., 2014; Rahman \& Anwar, 2014), but few are the studies that have explored the potential effects of organization-related factors such as ethical culture (Suh et al., 2018; Warren et al., 2014), ethical supervision (Brown \& Trevino, 2014; Shin et al., 2015), and ethics enforcement (Berenbeim, 2010; Campa, 2018; Ferrell, 2016), on this relationship.

There is evidence in the literature that ethics training contributes significantly to a strong ethical culture in the organization (Verschoor, 2014). However, it is highly likely that, despite the presence of elements of ethical culture such as an ethics code and formal policies, banking-sector employees at various organizational levels may indeed behave in a way that undermines the bank's compliance with ethical standards if they have supervision that disregards ethical standards and/or a deficiency in enforcing ethical compliance policies. Therefore, the hypotheses formulated by this study were:

H1: Ethical supervision mediates the relationship between ethics-training and the bank's ethical culture.

$\mathrm{H} 2$ : There is a significant and negative relationship between lack of ethics enforcement and the bank's ethical culture.

H3: There is a significant relationship between the bank's ethical culture and employees' ethical intentions.

This paper fills a gap in the literature by suggesting, confirming, and measuring the potentially co-existing effects of organization-related factors, like ethics enforcement and ethical supervision, on the relationship between ethics-training and employee behavior in the banking sector. The rest of this paper will present the methodology used in this research, the main findings and implications, followed by a conclusion section highlighting the study's implications, limitations and avenues for future research.

\section{METHODOLOGY}

The study aims to examine the effectiveness of Ethics-Training programs in influencing employees' ethical behavior. Special focus is on the roles of the bank's ethical culture, the ethical supervisor, and ethics policy enforcement or lack thereof.

Using the quantitative approach, the authors deemed structural equation modelling technique (SEM) to be the most appropriate statistical method as it helps simultaneously assess the relationships among the latent variables in the study. The authors used covariance-based SEM to assess model-fit, and SmartPLS (3) was used for this purpose (Ringle et al., 2015).

The measures were adapted from a global study by the American Management Association on the ethical enterprise (Forcade, 2005), where only 22 theory-related items were included in the survey, representing 5 constructs: ethics-training ( 4 items), ethical culture (6 items), supervisory non-compliance (4 items), lack of ethical policy enforcement (4 items), and ethical intention (4 items) as proxy for ethical behavior (Ajzen \& Fishbein, 1980). Three control variables were employed in the study: Age, Gender, and organizational position at the bank as such variables were found to be related to ethical behavior (Collins, 2000).

The survey was distributed to employees of various hierarchical levels working in the Lebanese banking sector. Only Alpha banks were targeted for respondents as they were known for their advanced ethics training programs, and the convenience sampling method was used as the authors could not obtain access to employee data due to the sensitive nature of the study and the sector. However, to increase the reliability of the data, the authors triangulated the data through informal conversations with at least one branch manager of each Alpha bank. Data from 258 surveys were analyzed using SmartPLS (3), and results were reported in the relevant tables and figures in the findings section below.

\section{Findings}

The findings of this study shed light on the dynamics of the relationship between ethics-training and employee ethical intentions. This relationship was already established in the literature, but there was a need to understand the factors that positively or negatively mediate this relationship, so that banking institutions may take the necessary measures that enhance the effectiveness of ethics-training programs on employee ethical behavior. 
Assessing the measurement model suggests that the data have adequate reliability and validity. All Cronbach's alpha and composite reliabilities exceed the recommended cutoff of 0.7 (Nunnally \& Bernstein 1994). Furthermore, all AVE scores exceeded the 0.5 threshold (Table 1), and the Fornell-Larcker (1981) criterion was met (Table 2 ) indicating adequate discriminant validity.

Table 1. Construct Reliability \& Validity

\begin{tabular}{|l|c|c|c|}
\hline & Cronbach's Alpha & $\begin{array}{c}\text { Composite } \\
\text { Reliability }\end{array}$ & $\begin{array}{c}\text { Average Variance } \\
\text { Extracted (AVE) }\end{array}$ \\
\hline Ethical Culture & 0.925 & 0.944 & 0.771 \\
\hline Ethical Intention & 0.863 & 0.908 & 0.712 \\
\hline Ethical Supervisor & 0.902 & 0.932 & 0.775 \\
\hline $\begin{array}{l}\text { Lack of Ethics } \\
\text { Enforcement }\end{array}$ & 0.901 & 0.928 & 0.763 \\
\hline Ethics Training & 0.838 & 0.891 & 0.672 \\
\hline
\end{tabular}

Table 2. Discriminant Validity

\begin{tabular}{|l|c|c|c|c|c|}
\hline & $\begin{array}{c}\text { Ethical } \\
\text { Culture }\end{array}$ & $\begin{array}{c}\text { Ethical } \\
\text { Intention }\end{array}$ & $\begin{array}{c}\text { Ethical } \\
\text { Supervisor }\end{array}$ & $\begin{array}{c}\text { Lack of Ethics } \\
\text { Enforcement }\end{array}$ & $\begin{array}{c}\text { Ethics } \\
\text { Training }\end{array}$ \\
\hline Ethical Culture & $\mathbf{0 . 8 7 8}$ & & & & \\
\hline Ethical Intention & 0.475 & $\mathbf{0 . 8 4 4}$ & & & \\
\hline Ethical Supervisor & 0.780 & 0.430 & $\mathbf{0 . 8 8 0}$ & & \\
\hline $\begin{array}{l}\text { Lack of Ethics } \\
\text { Enforcement }\end{array}$ & -0.602 & -0.239 & -0.586 & $\mathbf{0 . 8 7 4}$ & \\
\hline Ethics Training & 0.757 & 0.550 & 0.721 & -0.483 & $\mathbf{0 . 8 2 0}$ \\
\hline
\end{tabular}

The results of this study explain how organization-related factors may influence the effectiveness of ethicstraining. Specifically, all three hypothesized relationships were confirmed as follows. First, the relationship betweeen ethics training and ethical culture was mediated by the ethical behavior of the supervisor. This mediation was revealed by the change in the beta coefficient in the presence and absence of the ethical supervisor. The relationship between ethics training and ethical culture without mediation effects was highly significant $(B=0.644 ; p<0.000)$ as can be seen in Figure 1 . With mediation, the value of beta coefficient changed $(B=0.395 ; p<0.000)$, indicating a mediating effect of ethical supervision on this relationship (Figure 2). As SmartPLS can single out the indirect effects in a model, the Specific Indirect Effects showed a significant relationship between Ethics training and Ethical Culture, mediated by the Ethical Supervisor which had a singled-out significant mediation effect of $(B=0.306 ; p=0.006)$, thereby confirming the first hypothesis. 


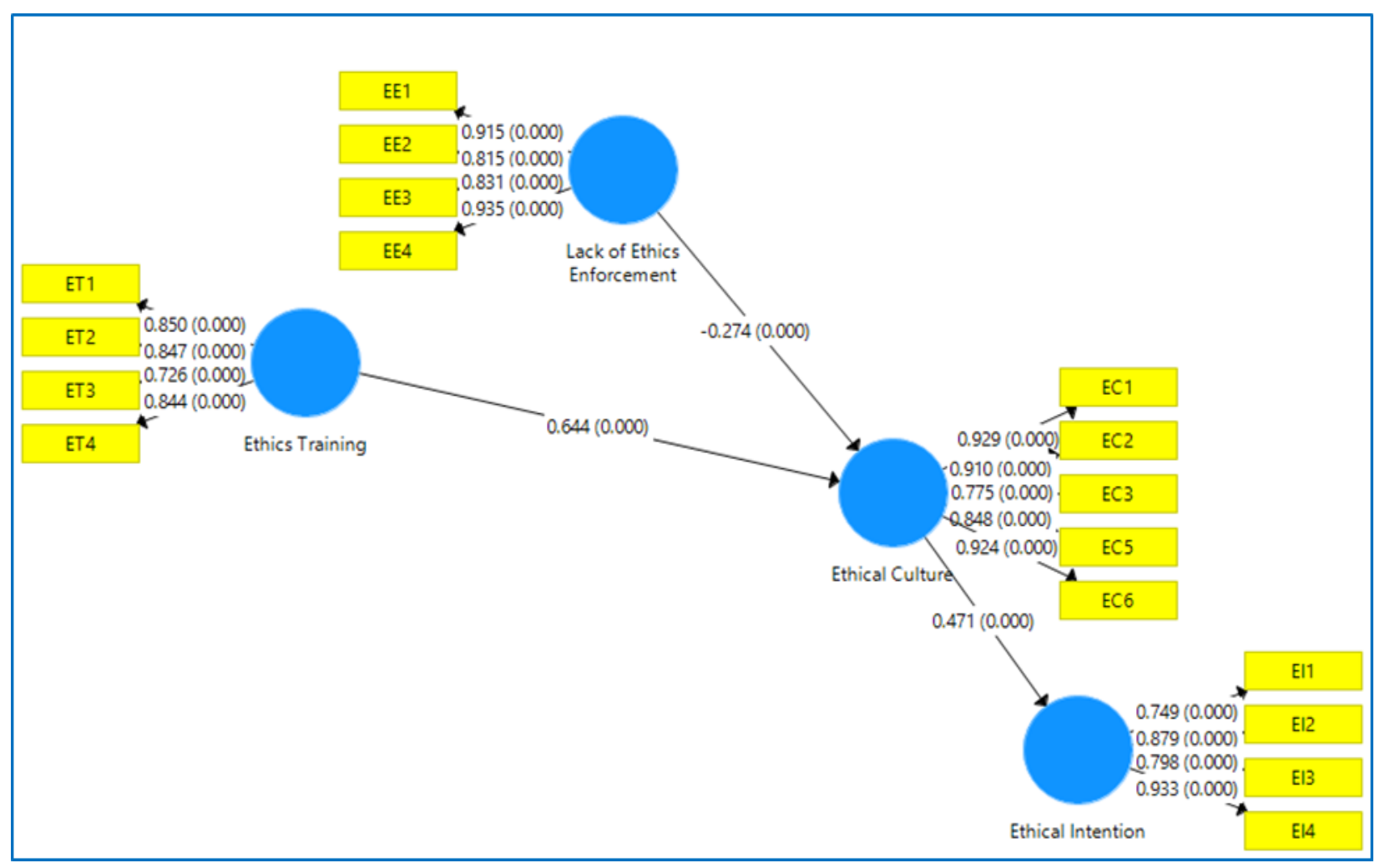

Figure 1. Bootstrapping without mediation

Second, the data analysis confirmed the significant but negative role played by lack of ethics enforcement in shaping the ethical culture at the bank $(B=-0.196 ; p=0.028)$, confirming the importance of ethics enforcement for harnessing the greatest impact from ethics training programs. Therefore, the second hypothesis in this study was confirmed.

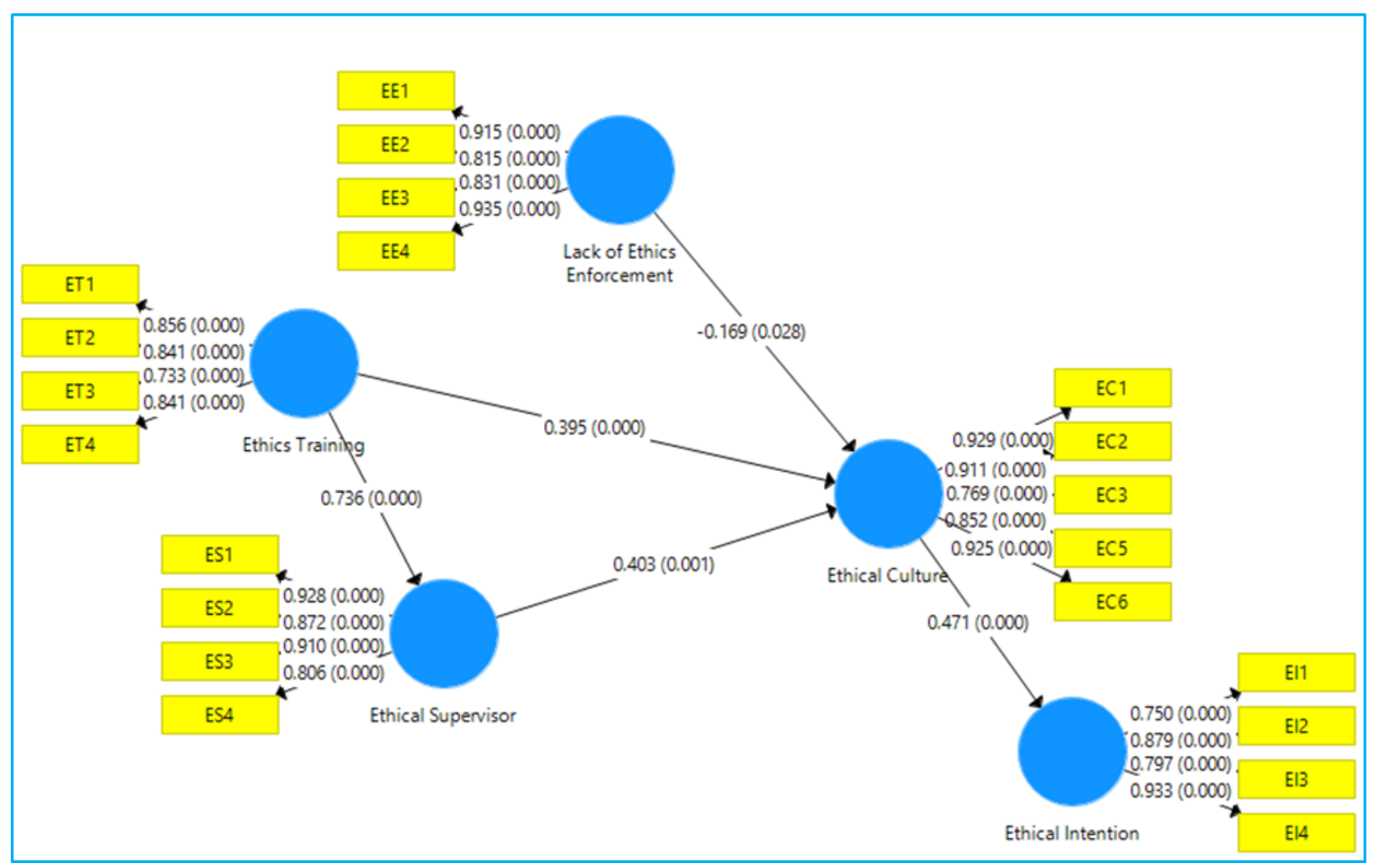

Figure 2: Bootstrapping with Mediation 
Third, the data analysis revealed a significant relationship between ethical culture and employees' ethical intentions $(B=0.471 ; p=0.000)$, given the afore-mentioned organization-related factors affecting the ethical culture of a bank, namely ethical supervision and ethical policy enforcement. Thus, the third hypothesis in this study was confirmed.

The findings in this study suggest that banks which invest in ethics training programs can maximize the benefits of these programs by focusing on the ethical compliance of supervisors, and on ethical policy enforcement. Though this may seem to be a challenging task, the fact that both factors are within the organization's control could make it easier. Ethical supervision and ethics enforcement are two factors that are internal to the organization and could be managed through internal control systems. These findings suggest that harnessing the positive effects of ethics training is significantly influenced by the organization-related factors, namely ethical supervision and enforcement.

\section{CONCLUSIONS}

The general conclusions derived from this study are insightful. Banking institutions need to understand that organization-related factors could influence the effectiveness of ethics-training programs, and that these factors can actually be influenced by specific measures taken by the bank itself. This is the value of this study for banking institutions.

Ethical culture could be enhanced by making sure that its elements are integral to the functioning of the bank. Supervisory compliance could be enhanced by offering targeted ethics training, incentives, and accountability measures. Enforcement of ethics policies could be implemented through ethics-audits, enforceable whistleblowing policies and effective reporting mechanisms. All these measures could be implemented by the banking institution so as to render the organization-related factors more conducive to ethical behavior on the part of bank employees.

Though this research has generated some interesting findings on the dynamics of making ethics training more effective, these findings must be used with caution, as the study addressed the issue of ethics-training in the Lebanese banking sector only. Similar training in other sectors and within other regions may be affected by a myriad of other factors that warrant analogous consideration. Moreover, Alpha banks in Lebanon are the largest and most profitable in the country and usually follow international standards in all their functions. As such, these banks may have developed an advanced ethical culture with better supervisory control and policy enforcement procedures, which likely affect respondents' perceptions of the organization-related factors under study. Having approached respondents working at Alpha banks only, the authors caution of possible sample bias. A future study in this area would do well to include the other bank categories (Beta, Gamma, and Delta) in order to capture any possible nuances in the relationships under study.

\section{REFERENCES}

Berenbeim, R. E. (2010). Utilizing HR and ethics and compliance collaboration to promote an ethical culture. Employment Relations Today, 37(1), 17-26.

Brown, M. E., \& Treviño, L. K. (2014). Do role models matter? An investigation of role modeling as an antecedent of perceived ethical leadership. Journal of Business Ethics, 122(4), 587-598.

Campa, D. (2018). Regulatory enforcement and the effectiveness of fraud training: A European investigation into earnings manipulation. Comptabilité-Contrôle-Audit, 24(1), 81-111.

Collins, D.: 2000, 'The Quest to Improve the Human Condition, Journal of Business Ethics, 26, pp.1-73.

Ferrell, O. C. (2016). A framework for understanding organizational ethics. In Business ethics: New challenges for business schools and corporate leaders (pp. 15-29). Routledge.

Forcade, W.J. (2005). The Ethical Enterprise, Doing the right things in the right ways, today and tomorrow, The American Management Association, N.Y.

Fornell, C., \& Larcker, D. F. (1981). Structural equation models with unobservable variables and measurement error: Algebra and statistics. Journal of marketing research, 382-388.

Hair Jr, J. F., Hult, G. T. M., Ringle, C., \& Sarstedt, M. (2016). A primer on partial least squares structural equation modeling (PLS-SEM). Sage Publications, N.Y.

Shin, Y., Sung, S. Y., Choi, J. N., \& Kim, M. S. (2015). Top management ethical leadership and firm performance: Mediating role of ethical and procedural justice climate. Journal of Business Ethics, 129(1), 43-57. 
Suh, J. B., Shim, H. S., \& Button, M. (2018). Exploring the impact of organizational investment on occupational fraud: Mediating effects of ethical culture and monitoring control. International Journal of Law, Crime and Justice, 53, 46-55.

May, D. R., Luth, M. T., \& Schwoerer, C. E. (2014). The influence of business ethics education on moral efficacy, moral meaningfulness, and moral courage: A quasi-experimental study. Journal of Business Ethics, 124(1), 67-80.

Warren, D. E., Gaspar, J. P., \& Laufer, W. S. (2014). Is formal ethics training merely cosmetic? A study of ethics training and ethical organizational culture. Business Ethics Quarterly, 24(1), 85-117.

Verschoor, C. C. (2014). Training is critical for a strong ethical culture. Strategic Finance, 96(3), 13-14. 